Original Research Paper

\title{
Numerical Solution of First Order Initial Value Problems Using a Self-Starting Implicit Two-Step Obrechkoff-Type Block Method
}

\author{
Zurni Omar and Oluwaseun Adeyeye \\ Department of Mathematics, School of Quantitative Sciences, Universiti Utara Malaysia, Sintok, Kedah, Malaysia
}

\author{
Article history \\ Received: 26-11-2015 \\ Revised: $14-04-2016$ \\ Accepted: 13-06-2016 \\ Corresponding Author: \\ Oluwaseun Adeyeye \\ Department of Mathematics, \\ School of Quantitative \\ Sciences, Universiti Utara \\ Malaysia, Sintok, Kedah, \\ Malaysia \\ Email: adeyeye oluwaseun@ahsgs.uum.edu.my
}

\begin{abstract}
The conventional two-step implicit Obrechkoff method is a discrete scheme that requires additional starting values when implemented for the numerical solution of first order initial value problems. This paper therefore presents a two-step implicit Obrechkoff-type block method which is self-starting for solving first order initial value problems, hence bypassing the rigour of developing and implementing new starting values for the method. Numerical examples are considered to show the new method performing better when com-pared with previously existing methods in literature.
\end{abstract}

Keywords: Two-Step, Obrechkoff Method, Block Method, Self-Starting

\section{Introduction}

In a bid to model real-life problems in areas of engineering, biological sciences, physical sciences, electronics and many others, initial value problems are most times encountered (Shokri and Shokri, 2013). A sample first order initial value problem takes the form given below:

$y^{\prime}=f(x, f), y(a)=\alpha$

However in most cases, these initial value problems cannot be solved analytically and hence the need for numerical methods. These numerical methods are adopted to obtain an approximate solution to the initial value problem under consideration (James et al., 2013). Numerous numerical approaches have been proposed by scholars for the numerical approximation of initial value problems. These methods range from discrete schemes (Lambert, 1973; Butcher, 2008; Fatunla, 1988), to predictor-corrector methods (Kayode and Adeyeye, 2011; Adesanya et al., 2008; Awoyemi and Idowu, 2005) and then block methods (Omar and Kuboye, 2015; Hasni et al., 2013; Areo and Adeniyi, 2013).

One distinct family of methods for the numerical approximation of (1) above is the Obrechkoff methods. This family of methods is regarded to be distinct due to the presence of higher derivatives in the method. The general form of the $k$-step Obrechkoff method with $l$ derivatives of $y$ is given by Lambert (1973) as: $\sum_{j=0}^{k} \alpha_{j} y_{n+j}=\sum_{i=1}^{l} h^{i} \sum_{j=0}^{k} \beta_{i j} y_{n+j}^{(i)} ; \alpha_{k}=+1$

with the implicit $k=2 ; l=2$ Adams-type method given as:

$$
\begin{aligned}
& y_{n+2}-y_{n+1}=\frac{h}{240}\left(101 y_{n+2}^{(1)}+128 y_{n+1}^{(1)}+11 y_{n}^{(1)}\right) \\
& +\frac{h^{2}}{240}\left(-13 y_{n+2}^{(2)}+40 y_{n+1}^{(2)}+3 y_{n}^{(2)}\right)
\end{aligned}
$$

However, adopting the method presented in Equation 3 above requires the introduction of additional one-step numerical methods such as Euler or Trapezoidal method. This approach most times does not provide optimal accuracy and hence the need to adopt block methods. Block methods have been found to give better approximation as seen in the studies by (Jator and Li, 2012; Omar, 2004; Adesanya et al., 2014) amongst many others. Hence, this work presents a self-starting block method that will bypass the rigour of developing separate starting values and also with expected better accuracy when compared to previously existing methods in literature.

The second section of this article will show how the block method is derived and also discuss some basic properties of the block method while the next section will present some numerical examples and results. The fourth section of this article concludes this work. 


\section{The Two-Step Implicit Obrechkoff-Type} Block Method

Consider an implicit $k=2 ; l=2$ Nyström-type form (Lambert, 1973) of Equation 2 above which can be written as:

$$
y_{n+2}=\sum_{j=0}^{k-2} \alpha_{j} y_{n+j}+\sum_{i=1}^{l} h^{i} \sum_{j=0}^{k} \beta_{i j} y_{n+j}^{(i)}
$$

Expanding each term in (4) above using Taylor series gives the following expression:

$$
\begin{aligned}
& y\left(x_{n}\right)+h y^{\prime}\left(x_{n}\right)+\frac{(2 h)^{2}}{2 !} y^{\prime \prime}\left(x_{n}\right)+\frac{(2 h)^{3}}{3 !} y^{\prime \prime \prime}\left(x_{n}\right) \frac{(2 h)^{4}}{4 !}+y^{i v}\left(x_{n}\right) \frac{(2 h)^{5}}{5 !}+y^{v}\left(x_{n}\right) \frac{(2 h)^{6}}{6 !} y^{v i}\left(x_{n}\right) \\
& =\alpha_{0} y\left(x_{n}\right)+h\left[\begin{array}{l}
\beta_{10} y^{\prime}\left(x_{n}\right)+\beta_{11}\left(y^{\prime}\left(x_{n}\right)+h y^{\prime \prime}\left(x_{n}\right)+\frac{h^{2}}{2 !} y^{\prime \prime \prime}\left(x_{n}\right)+\frac{h^{3}}{3 !} y^{i v}\left(x_{n}\right)+\frac{h^{4}}{4 !} y^{v}\left(x_{n}\right)+\frac{h^{5}}{5 !} y^{v i}\left(x_{n}\right)\right) \\
+\beta_{12}\left(y^{\prime}\left(x_{n}\right)+2 h y^{\prime \prime}\left(x_{n}\right)+\frac{(2 h)^{2}}{2 !} y^{\prime \prime \prime}\left(x_{n}\right)+\frac{(2 h)^{3}}{3 !} y^{i v}\left(x_{n}\right)+\frac{(2 h)^{4}}{4 !} y^{\nu}\left(x_{n}\right)+\frac{(2 h)^{5}}{5 !} y^{v i}\left(x_{n}\right)\right)
\end{array}\right] \\
& +h^{2}\left[\beta_{20}\left(y^{\prime \prime}\left(x_{n}\right)+\beta_{21}\left(y^{\prime \prime}\right)\left(x_{n}\right)+h y^{\prime \prime \prime}\left(x_{n}\right)+\frac{h^{2}}{2 !} y^{i v}\left(x_{n}\right)+\frac{h^{3}}{3 !} y^{\nu}\left(x_{n}\right)+\frac{h^{4}}{4 !} y^{i v}\left(x_{n}\right)\right)+\beta_{22}\left(\begin{array}{l}
y^{\prime \prime}\left(x_{n}\right)+2 h y^{\prime \prime \prime}\left(x_{n}\right)+\frac{(2 h)^{2}}{2 !} y^{i v}\left(x_{n}\right) \\
+\frac{(2 h)^{3}}{3 !} y^{\nu}\left(x_{n}\right)+\frac{(2 h)^{4}}{4 !} y^{v i}\left(x_{n}\right)
\end{array}\right)\right]
\end{aligned}
$$

Where:

$$
\begin{aligned}
& y_{n+a}=y\left(x_{n}+a h\right)=y\left(x_{n}\right) \\
& +a h y^{\prime}\left(x_{n}\right)+\frac{(a h)^{2}}{2 !} y^{\prime \prime}\left(x_{n}\right)+\frac{(a h)^{3}}{3 !} y^{\prime \prime \prime}\left(x_{n}\right)+\ldots
\end{aligned}
$$

Rewriting this expression in matrix form, where the coefficients of $h^{i} y^{(i)}\left(x_{n}\right)$ are equated gives:

$$
\left(\begin{array}{ccccccc}
1 & 0 & 0 & 0 & 0 & 0 & 0 \\
0 & 1 & 1 & 1 & 0 & 0 & 0 \\
0 & 0 & 1 & 2 & 1 & 1 & 1 \\
0 & 0 & \frac{(1)^{2}}{2 !} & \frac{(2)^{2}}{2 !} & 0 & 1 & 2 \\
0 & 0 & \frac{(1)^{3}}{3 !} & \frac{(2)^{3}}{3 !} & 0 & \frac{(1)^{2}}{2 !} & \frac{(2)^{2}}{2 !} \\
0 & 0 & \frac{(1)^{4}}{4 !} & \frac{(2)^{4}}{4 !} & 0 & \frac{(1)^{2}}{3 !} & \frac{(2)^{3}}{3 !} \\
0 & 0 & \frac{(1)^{5}}{5 !} & \frac{(2)^{5}}{5 !} & 0 & \frac{(1)^{4}}{4 !} & \frac{(2)^{4}}{4 !}
\end{array}\right)\left(\begin{array}{c}
\alpha_{0} \\
\beta_{10} \\
\beta_{11} \\
\beta_{12} \\
\beta_{20} \\
\beta_{21} \\
\beta_{22}
\end{array}\right)=\left(\begin{array}{c}
1 \\
2 \\
\frac{(2)^{2}}{2 !} \\
\frac{(2)^{3}}{3 !} \\
\frac{(2)^{4}}{4 !} \\
\frac{(2)^{5}}{5 !} \\
\frac{(2)^{6}}{6 !}
\end{array}\right)
$$

with values of $\left(\alpha_{0}, \beta_{10}, \beta_{11}, \beta_{12}, \beta_{20}, \beta_{21}\right.$ and $\left.\beta_{22}\right)$ obtained to be:

$$
\begin{aligned}
& \left(\alpha_{0}, \beta_{10}, \beta_{11}, \beta_{12}, \beta_{20}, \beta_{21} \text { and } \beta_{22}\right)^{T} \\
& =\left(1, \frac{7}{15}, \frac{16}{15}, \frac{7}{15}, \frac{1}{15}, 0,-\frac{1}{15}\right)^{T}
\end{aligned}
$$

Substituting the values of $\alpha_{0}, \beta_{10}, \beta_{11}, \beta_{12}, \beta_{20}, \beta_{21}$ and $\beta_{22}$ obtained in Equation 6 above back in Equation 4 gives the two-step implicit method:

$$
y_{n+2}=y_{n}+\frac{h}{15}\left(7 y_{n}^{(1)}+16 y_{n+1}^{(1)}+7 y_{n+2}^{(1)}\right)+\frac{h^{2}}{15}\left(y_{n}^{(2)}-y_{n+2}^{(2)}\right)
$$

However, to implement the method derived in Equation 7, an additional method is needed.

This method is obtained by considering the following two-step method given as:

$$
y_{n+1}=\sum_{j=0}^{k-2} \alpha_{j} y_{n+j}+\sum_{i=1}^{l} h^{i} \sum_{j=0}^{k} \beta_{i j} y_{n+j}^{(i)}
$$

Following the same steps adopted for deriving the implicit $k=2 ; l=2$ Nyström-type method given in Equation 7, the additional method is derived to give:

$$
\begin{aligned}
& y_{n+1}-y_{n}=\frac{h}{240}\left(101 y_{n}^{(1)}+128 y_{n+1}^{(1)}+11 y_{n+2}^{(1)}\right) \\
& +\frac{h^{2}}{240}\left(-13 y_{n}^{(2)}+40 y_{n+1}^{(2)}+3 y_{n+2}^{(2)}\right)
\end{aligned}
$$

Hence, Equation 7 and 9 present the desired block method for the solution of (1).

However, to check for the order and the convergence of this block method, the following theorem and definitions are adopted.

\section{Theorem 2.1 (Fatunla, 1988)}

A linear multistep method is convergent iff it is consistent and zero-stable.

Definition 2.1 (Jator and Li, 2012)

A linear multistep method is consistent if it has order $p \geq 1$. 


\section{Definition 2.2 (Butcher, 2008)}

The linear operator associated with Equation 2 is defined as:

$$
L[y(x) ; h]=\sum_{j=0}^{k} \alpha_{j} y_{n+j}-\sum_{i=1}^{l} h^{i} \sum_{j=0}^{k} \beta_{i j} y_{n+j}^{(i)}
$$

Expanding $y_{n+j}$ and $y_{n+j}^{(i)}$ using Taylor series to obtain:

$$
\begin{aligned}
& L[y(x) ; h]=C_{0 y}\left(x_{n}\right)+C_{1} h y^{\prime}\left(x_{n}\right)+C_{2} h^{2} y^{\prime \prime}\left(x_{n}\right) \\
& +\ldots+C_{q} h^{q} y^{q}\left(x_{n}\right)+C_{q+1} h^{q+1} y^{q+1}\left(x_{n}\right)
\end{aligned}
$$

The method is said to be of order $q$ if $C_{0}=C_{1}=\ldots=$ $C_{q}=0, C_{q+1} \neq=0$ and $C_{q+1}$ is the error constant.

The order of the block method in Equations 7 and 9 is gotten from:

$$
\begin{aligned}
& C_{0}=\left(\begin{array}{l}
-1+1 \\
-1+1
\end{array}\right)=\left(\begin{array}{l}
0 \\
0
\end{array}\right) \\
& C_{1}\left(\begin{array}{l}
1-\frac{1}{240}[101(1)+128(1)+11(1)] \\
2-\frac{1}{15}[7(1)+16(1)+7(1)]
\end{array}\right)=\left(\begin{array}{l}
0 \\
0
\end{array}\right) \\
& C_{2}=\left(\begin{array}{l}
\frac{(1)^{2}}{2 !}-\frac{1}{240}[101(0)+128(1)+11(2)]-\frac{1}{240}[13(1)-40(1)-3(1)] \\
\frac{(2)^{2}}{2 !}-\frac{1}{15}[7(0)+16(1)+7(2)]-\frac{1}{15}[1(1)-1(1)]
\end{array}\right)=\left(\begin{array}{l}
0 \\
0
\end{array}\right) \\
& C_{3}=\left(\begin{array}{l}
\frac{(1)_{3}}{3 !}-\frac{1}{240}\left[101(0)+128\left(\frac{(1)^{2}}{2 !}\right)+11\left(\frac{(2)^{2}}{2 !}\right)\right]-\frac{1}{240}[13(0)-40(1)-3(2)] \\
\frac{(2)^{3}}{3 !}-\frac{1}{15}\left[7(0)+16\left(\frac{(1)^{2}}{2 !}\right)+7\left(\frac{(2)^{2}}{2 !}\right)-\frac{1}{15}[1(0)-1(2)]\right.
\end{array}\right)=\left(\begin{array}{l}
0 \\
0
\end{array}\right) \\
& C_{4}=\left(\begin{array}{l}
\frac{(1)^{4}}{4 !}-\frac{1}{240}\left[101(0)+128\left(\frac{(1)^{3}}{3 !}\right)+11\left(\frac{(2)^{3}}{3 !}\right)\right]-\frac{1}{240}\left[13(0)-40\left(\frac{(1)^{2}}{2 !}\right)-3\left(\frac{(2)^{2}}{2 !}\right)\right] \\
\frac{(2)^{4}}{4 !}-\frac{1}{15}\left[7(0)+16\left(\frac{(1)^{3}}{3 !}\right)+7\left(\frac{(2)^{3}}{3 !}\right)\right]-\frac{1}{15}\left[1(0)-1\left(\frac{(2)^{2}}{2 !}\right)\right]
\end{array}\right)=\left(\begin{array}{l}
0 \\
0
\end{array}\right) \\
& C_{5}=\left(\begin{array}{l}
\frac{(1)^{5}}{5 !}-\frac{1}{240}\left[101(0)+128\left(\frac{(1)^{4}}{4 !}\right)+11\left(\frac{(2)^{4}}{4 !}\right)\right]-\frac{1}{240}\left[13(0)-40\left(\frac{(1)^{3}}{3 !}\right)-3\left(\frac{(3)^{3}}{3 !}\right)\right] \\
\frac{(2)^{5}}{5 !}-\frac{1}{15}\left[7(0)+16\left(\frac{(1)^{4}}{4 !}\right)+7\left(\frac{(2)^{4}}{4 !}\right)\right]-\frac{1}{15}\left[1(0)-1\left(\frac{(2)^{3}}{3 !}\right)\right]
\end{array}\right)=\left(\begin{array}{l}
0 \\
0
\end{array}\right) \\
& C_{6}=\left(\begin{array}{l}
\frac{(1)^{6}}{6 !}-\frac{1}{240}\left[101(0)+128\left(\frac{(1)^{5}}{5 !}\right)+11\left(\frac{(2)^{5}}{5}\right)\right]-\frac{1}{240}\left[13(0)-40\left(\frac{(1)^{4}}{4 !}\right)-3\left(\frac{(2)^{4}}{4 !}\right)\right] \\
\frac{(2)^{6}}{6 !}-\frac{1}{15}\left[7(0)+16\left(\frac{(1)^{5}}{5 !}\right)+7\left(\frac{(2)^{5}}{5 !}\right)\right]-\frac{1}{15}\left[1(0)-1\left(\frac{(2)^{4}}{4 !}\right)\right]
\end{array}\right)=\left(\begin{array}{l}
0 \\
0
\end{array}\right) \\
& C_{7}=\left(\begin{array}{l}
\frac{(1)^{7}}{7 !}-\frac{1}{240}\left[101(0)+128\left(\frac{(1)^{6}}{6 !}\right)+11\left(\frac{(2)^{6}}{6 !}\right)\right]-\frac{1}{240}\left[13(0)-40\left(\frac{(1)^{5}}{5 !}\right)-3\left(\frac{(2)^{5}}{5 !}\right)\right] \\
\frac{(2)^{7}}{7 !}-\frac{1}{15}\left[7(0)+16\left(\frac{(1)^{6}}{6 !}\right)+7\left(\frac{(2)^{6}}{6 !}\right)\right]-\frac{1}{15}\left[1(0)-1\left(\frac{(2)^{5}}{5 !}\right)\right]
\end{array}\right)=\left(\begin{array}{l}
\frac{1}{4725} \\
\frac{1}{9450}
\end{array}\right)
\end{aligned}
$$

This implies that the block method has order $p=6$ with error constant $C_{7}=\left(\frac{1}{4725}, \frac{1}{9450}\right)^{T}$.

Hence, the block method is consistent.

\section{Definition 2.3 (Jator and Li, 2012)}

A block method is said to be zero-stable if after normalizing and writing the block method in the following matrix difference equation form: 
$A^{0} Y_{\mu+1}=A^{0} Y_{\mu}+h^{m}\left[B^{0} F_{\mu+1}+B^{1} F_{\mu}\right]+h^{m-1} C^{1} \Delta_{\mu}$

where, $Y_{\mu+1}=\left(y_{n+1}, \ldots, y_{n+k}\right)^{T}, Y_{\mu}=\left(y_{n-(k-1)}, \ldots, y_{n}\right)^{T}, F_{\mu+1}=$ $\left(f_{n+1}, \ldots, f_{n+k}\right)^{T}, F_{\mu}=\left(f_{n-(k-1)}, \ldots, f_{n}\right), \Delta_{\mu}=\left(\delta_{n-(k-1)}, \ldots, \delta_{n}\right)^{T}, \mu=0$, $1, \ldots$, the first characteristic polynomial takes the form:

$$
\rho(R)=\operatorname{det}\left(R A^{0}-A^{1}\right)
$$

and the roots of $\rho(R)=0$ satisfy $\left|R_{j}\right| \leq 1, j=1, \ldots, k$.

Adopting this approach to the block methods to test for zero stability, the block method is normalized to give the first characteristic polynomial as:

$$
\rho(R)=\operatorname{det}\left(R A^{0}-A^{1}\right)=R(R-1)
$$

The roots of $\rho(R)=0$ satisfy $\left|R_{j}\right| \leq 1, j=1,2$. Hence, the block is said to be zero-stable.
Therefore, since the block method is consistent and zero-stable, it is likewise convergent.

The region of absolute stability is determined by obtaining the stability polynomial from:

$\operatorname{det}\left[\sum_{i=0}^{k} A^{i} q^{k-i}+z \sum_{i=0}^{k} B^{i} q^{k-i}+z^{2} \sum_{i=0}^{k} C^{i} q^{k-i}\right], z=\lambda h$

Hence, the stability polynomial for the block method is gotten as:

$$
\begin{aligned}
& R(q)=\frac{q^{3} z^{4}}{90}-\frac{q^{3} z^{3}}{10}+\frac{13 q^{3} z^{2}}{30} \\
& -q^{3} z+q^{3}-\frac{q z^{4}}{90}-\frac{q z^{3}}{10}-\frac{q z^{2}}{30}-q z-q
\end{aligned}
$$

Plotting the roots of the stability polynomial in boundary locus approach displays the region of absolute stability as shown Fig. 1.

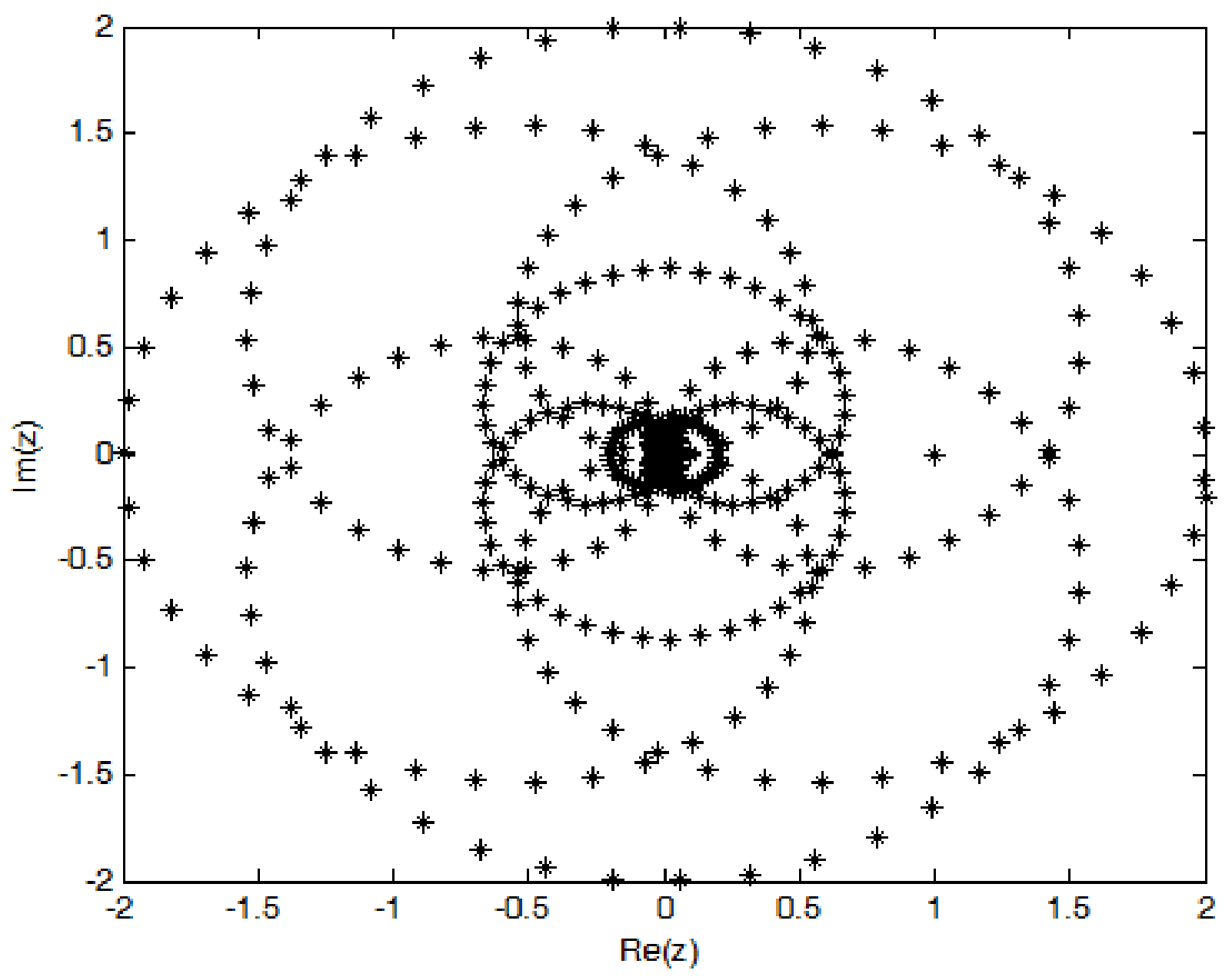

Fig. 1. Region of absolute stability for the two-step implicit Obrechkoff-Type block 


\section{Numerical Examples}

This section presents some numerical examples and corresponding results of the new two-Step ObrechkoffType block method in comparison to the two-step method in Equation 3 and other existing methods in recent literature.

The following notations are used in the tables of results:

- 2SEM: Two-Step Implicit Obrechkoff method in Equation 3

- 2SBM: New Two-Step Obrechkoff-Type Block Method

- Error: |Computed Solution-Exact Solution|

\section{Tested Problem 3.1 (Mixture Model)}

In an oil refinery, a storage tank contains 2000 gal of gasoline that initially has $100 \mathrm{lb}$ of an additive dissolved in it. In the preparation for winter weather, gasoline containing $2 \mathrm{lb}$ of additive per gallon is pumped into the tank at a rate of $40 \mathrm{gal} \mathrm{min}^{-1}$. The well-mixed solution is pumped out at a rate of $45 \mathrm{gal} \mathrm{min}^{-1}$. Using a numerical integrator, how much of the additive is in the tank 0.1, 0.5 and 1 min after the pumping process begins?

Let $y$ be the amount (in pounds) of additive in the tank at time $\mathrm{t}$. We know that $y=100$ when $t=0$. Thus, the Initial Value Problem (IVP) modeling the mixture process is:

$$
y^{\prime}=80-\frac{45 y}{(2000-5 t)}, y(0)=100, h=0.1
$$

with theoretical solution:

$$
y(t)=2(2000-5 t)-\frac{3900}{(2000)^{9}}(2000-5 t)^{9}
$$

Source: Sunday et al. (2013).

The numerical result is shown in Table $1 \mathrm{a}$ and $1 \mathrm{~b}$.

\section{Tested Problem 3.2 (SIR Model)}

The SIR model is an epidemiological model that computes the theoretical number of people infected with a contagious illness in a closed population over time. The name of this class of models derives from the fact that they involve coupled equations relating the number of susceptible people $S(t)$, number of people infected $I(t)$ and the number of people who have recovered $R(t)$. This is a good and simple model for many infectious diseases including measles, mumps and rubella. It is given by the following three coupled equations:

$\frac{d S}{d t}=\mu(1-S)-\beta I S$

$\frac{d I}{d t}=-\mu I-\gamma I+\beta I S$

$\frac{d R}{d t}=-\mu R+\gamma I$

Table 1a. Comparison of computed results for solving tested problem 3.1

\begin{tabular}{lllll}
\hline $\mathrm{T}$ & Exact solution & $\begin{array}{l}\text { Computed solution } \\
(\text { 2SEM) }\end{array}$ & $\begin{array}{l}\text { Computed solution } \\
\text { (Sunday et al., 2013) }\end{array}$ & $\begin{array}{l}\text { Computed solution } \\
(2 \mathrm{SBM})\end{array}$ \\
\hline 0.1 & 107.7662301168309486 & 107.76623267141251405 & 107.76623011683095 & 107.76623011683094855 \\
0.2 & 115.5149409193028512 & 115.51494346840455900 & 115.51494091930284 & 115.51494091930285113 \\
0.3 & 123.2461630508845221 & 123.24616814117862409 & 123.24616305088452 & 123.24616305088452198 \\
0.4 & 130.9599271090910725 & 130.95993218819786255 & 130.95992710909107 & 130.95992710909107252 \\
0.5 & 138.6562636455413535 & 138.65627125250773431 & 138.65626364554134 & 138.65626364554135350 \\
0.6 & 146.3352031660153396 & 146.33521075612409816 & 146.33520316601533 & 146.33520316601533957 \\
0.7 & 153.9967761305114566 & 153.99678623520317743 & 153.99677613051145 & 153.99677613051145660 \\
0.8 & 161.6410129533038516 & 161.64102303550463010 & 161.64101295330383 & 161.64101295330385157 \\
0.9 & 169.2679440029996051 & 169.26795658656269977 & 169.26794400299960 & 169.26794400299960502 \\
1.0 & 176.8775996025958863 & 176.87761215807155490 & 176.87759960259586 & 176.87759960259588643 \\
\hline
\end{tabular}

Table 1b. Comparison of error for solving tested problem 3.1

\begin{tabular}{llll}
\hline $\mathrm{T}$ & Error (2SEM) & $\begin{array}{l}\text { Error } \\
\text { (Sunday } \text { et al., 2013) }\end{array}$ & Error (2SBM) \\
\hline 0.1 & $2.554000 \mathrm{E}-06$ & $2.700062 \mathrm{E}-13$ & $5.000000 \mathrm{E}-17$ \\
0.2 & $2.549000 \mathrm{E}-06$ & $1.278977 \mathrm{E}-13$ & $7.000000 \mathrm{E}-17$ \\
0.3 & $5.090000 \mathrm{E}-06$ & $1.421085 \mathrm{E}-13$ & $1.200000 \mathrm{E}-16$ \\
0.4 & $5.079000 \mathrm{E}-06$ & $4.263256 \mathrm{E}-13$ & $2.000000 \mathrm{E}-17$ \\
0.5 & $7.607000 \mathrm{E}-06$ & $1.136868 \mathrm{E}-13$ & $0.000000 \mathrm{E}+00$ \\
0.6 & $7.590000 \mathrm{E}-06$ & $1.705303 \mathrm{E}-13$ & $3.000000 \mathrm{E}-17$ \\
0.7 & $1.010000 \mathrm{E}-05$ & $8.526513 \mathrm{E}-14$ & $0.000000 \mathrm{E}+00$ \\
0.8 & $1.008000 \mathrm{E}-05$ & $8.526513 \mathrm{E}-14$ & $3.000000 \mathrm{E}-17$ \\
0.9 & $1.258000 \mathrm{E}-05$ & $8.526513 \mathrm{E}-14$ & $8.000000 \mathrm{E}-17$ \\
1.0 & $1.256000 \mathrm{E}-05$ & $2.273737 \mathrm{E}-13$ & $1.300000 \mathrm{E}-16$ \\
\hline
\end{tabular}


Table 2a. Comparison of computed results for solving tested problem 3.2

\begin{tabular}{lllll}
\hline $\mathrm{T}$ & Exact solution & $\begin{array}{l}\text { Computed solution } \\
(\text { (SEM) }\end{array}$ & $\begin{array}{l}\text { Computed solution } \\
\text { (Sunday et al., 2013) }\end{array}$ & $\begin{array}{l}\text { Computed solution } \\
(2 \mathrm{SBM})\end{array}$ \\
\hline 0.1 & 0.52438528774964299546 & 0.52439024390243902439 & 0.5243852877552174 & 0.52438528774960472804 \\
0.2 & 0.54758129098202021342 & 0.54758601695347485034 & 0.5475812909859664 & 0.54758129098194536511 \\
0.3 & 0.56964601178747109638 & 0.56965499173623217471 & 0.5696460117956543 & 0.56964601178736527269 \\
0.4 & 0.59063462346100907066 & 0.59064317588795690893 & 0.5906346234953703 & 0.59063462346087361956 \\
0.5 & 0.61059960846429756588 & 0.61061180145439803533 & 0.6105996086572718 & 0.61059960846413739010 \\
0.6 & 0.62959088965914106696 & 0.62960249743238951881 & 0.6295908898470451 & 0.62959088965895722513 \\
0.7 & 0.64765595514064328282 & 0.64767066828934612765 & 0.6476559553183269 & 0.64765595514044005788 \\
0.8 & 0.66483997698218034963 & 0.66485398110580363236 & 0.6648399771546479 & 0.66483997698195855368 \\
0.9 & 0.68118592418911335343 & 0.68120256739332540639 & 0.6811859243738679 & 0.68118592418887672320 \\
1.0 & 0.69673467014368328820 & 0.69675050937978129410 & 0.6967346704442603 & 0.69673467014343242661 \\
\hline
\end{tabular}

Table 2b. Comparison of error for solving tested problem 3.2

\begin{tabular}{llll}
\hline $\mathrm{T}$ & Error (2SEM) & $\begin{array}{l}\text { Error } \\
\text { (Sunday et al., 2013) }\end{array}$ & Error (2SBM) \\
\hline 0.1 & $4.956150 \mathrm{E}-06$ & $5.574430 \mathrm{E}-12$ & $3.826740 \mathrm{E}-14$ \\
0.2 & $4.725970 \mathrm{E}-06$ & $3.946177 \mathrm{E}-12$ & $7.484830 \mathrm{E}-14$ \\
0.3 & $8.979940 \mathrm{E}-06$ & $8.183232 \mathrm{E}-12$ & $1.058240 \mathrm{E}-13$ \\
0.4 & $8.552430 \mathrm{E}-06$ & $3.436118 \mathrm{E}-11$ & $1.354510 \mathrm{E}-13$ \\
0.5 & $1.219300 \mathrm{E}-05$ & $1.929473 \mathrm{E}-10$ & $1.601760 \mathrm{E}-13$ \\
0.6 & $1.160780 \mathrm{E}-05$ & $1.879040 \mathrm{E}-10$ & $1.838420 \mathrm{E}-13$ \\
0.7 & $1.471310 \mathrm{E}-05$ & $1.776835 \mathrm{E}-10$ & $2.032250 \mathrm{E}-13$ \\
0.8 & $1.400410 \mathrm{E}-05$ & $1.724676 \mathrm{E}-10$ & $2.217960 \mathrm{E}-13$ \\
0.9 & $1.664320 \mathrm{E}-05$ & $1.847545 \mathrm{E}-10$ & $2.366300 \mathrm{E}-13$ \\
1.0 & $1.583920 \mathrm{E}-05$ & $3.005770 \mathrm{E}-10$ & $2.508620 \mathrm{E}-13$ \\
\hline
\end{tabular}

Table 3a. Comparison of computed results for solving tested problem 3.3

\begin{tabular}{lllll}
\hline $\mathrm{X}$ & Exact solution & $\begin{array}{l}\text { Computed solution } \\
(\text { 2SEM) }\end{array}$ & $\begin{array}{l}\text { Computed solution } \\
\text { (Badmus } \text { et al., 2015) }\end{array}$ & $\begin{array}{l}\text { Computed solution } \\
(2 \mathrm{SBM})\end{array}$ \\
\hline 0.1 & 0.90483741803595957316 & 0.90476190476190476190 & 0.904837417881202 & 0.90483741804503260091 \\
0.2 & 0.81873075307798185867 & 0.81866206899176567085 & 0.818730752939751 & 0.81873075309534995788 \\
0.3 & 0.74081822068171786607 & 0.74069425289731179744 & 0.740818220548903 & 0.74081822070486153894 \\
0.4 & 0.67032004603563930074 & 0.67020758320587849512 & 0.670320045918305 & 0.67032004606407889464 \\
0.5 & 0.60653065971263342360 & 0.60637828956722340034 & 0.606530659599218 & 0.60653065974444846468 \\
0.6 & 0.54881163609402643263 & 0.54867352672129543193 & 0.548811635994641 & 0.54881163612895298782 \\
0.7 & 0.49658530379140951470 & 0.49641890512879110507 & 0.496585303694640 & 0.49658530382799175192 \\
0.8 & 0.44932896411722159143 & 0.44917820458666454624 & 0.449328964033219 & 0.44932896415534885121 \\
0.9 & 0.40656965974059911188 & 0.40639932795936316088 & 0.406569659658082 & 0.40656965977917485733 \\
1.0 & 0.36787944117144232160 & 0.36772515831292540605 & 0.367879441100594 & 0.36787944121046227174 \\
\hline
\end{tabular}

Table 3b. Comparison of error for solving tested problem 3.3

\begin{tabular}{llll}
\hline $\mathrm{X}$ & Error (2SEM) & Error (Badmus et al., 2015) & Error (2SBM) \\
\hline 0.1 & $7.5513 \mathrm{E}-05$ & $1.5476 \mathrm{E}-10$ & $9.0730 \mathrm{E}-12$ \\
0.2 & $6.8684 \mathrm{E}-05$ & $1.3823 \mathrm{E}-10$ & $1.1768 \mathrm{E}-11$ \\
0.3 & $1.2397 \mathrm{E}-04$ & $1.3282 \mathrm{E}-10$ & $2.3144 \mathrm{E}-11$ \\
0.4 & $1.1246 \mathrm{E}-04$ & $1.1733 \mathrm{E}-10$ & $2.8440 \mathrm{E}-11$ \\
0.5 & $1.5237 \mathrm{E}-04$ & $1.1342 \mathrm{E}-10$ & $3.1815 \mathrm{E}-11$ \\
0.6 & $1.3811 \mathrm{E}-04$ & $9.9385 \mathrm{E}-11$ & $3.4927 \mathrm{E}-11$ \\
0.7 & $1.6640 \mathrm{E}-04$ & $9.6770 \mathrm{E}-11$ & $3.6582 \mathrm{E}-11$ \\
0.8 & $1.5076 \mathrm{E}-04$ & $8.4003 \mathrm{E}-11$ & $3.8127 \mathrm{E}-11$ \\
0.9 & $1.7033 \mathrm{E}-04$ & $8.2517 \mathrm{E}-11$ & $3.8576 \mathrm{E}-11$ \\
1.0 & $1.5428 \mathrm{E}-04$ & $7.0848 \mathrm{E}-11$ & $3.9020 \mathrm{E}-11$ \\
\hline
\end{tabular}

where, $\mu, \gamma$ and $\beta$ are positive parameters. Define y to be: and adding Equations 13-15, we obtain the following evolution equation for $y$ :

$$
y=S+I+R
$$

$$
y^{\prime}=\mu(1-y)
$$


Taking $\mu=0.5$ and attaching an initial condition $y(0)$ $=0.5$ (for a particular closed population), we obtain:

$$
y^{\prime}=(t)=0.5(1-y), y(0)=0.5, h=0.1
$$

with exact solution:

$$
y(t)=1-0.5 e^{-0.5 t}
$$

Source: Sunday et al. (2013).

The numerical result is shown in Table $2 \mathrm{a}$ and $2 \mathrm{~b}$.

\section{Tested Problem 3.3}

$$
\begin{gathered}
y^{\prime}=-y, y(0)=1, h=0.1 \\
y(x)=e^{-x}
\end{gathered}
$$

Source: Badmus et al. (2015).

The numerical result is shown in Table $3 \mathrm{a}$ and $3 \mathrm{~b}$.

\section{Conclusion}

The work presents a two-step implicit Obrechkofftype block method which does not require the use of starting values in its implementation. The method was used to solve some numerical examples and the results were compared with the already existing two-step Obrechkoff method which required starting values for its implementation. The results gotten in the tables above showed the new block method having a far better accuracy when compared to the exact solution. Also, the block method was compared to some recent literature and the block method also showed better accuracy although this article only considered the solution of first order initial value problems with analytical solution because the aim of the article is to show how close the numerical solution obtained (by adopting the new block method) is to the exact solution. It is worth taking note of that the methods used in comparison are also methods with equal order (order 6). Hence, the basis of comparison is fair and this new method is proposed for adoption when solving first order initial value problems.

\section{Acknowledgement}

The authors gratefully acknowledge the support of Research and Innovation Centre (RIMC), Universiti Utara Malaysia in helping us in terms of adminstrative work for the purpose of publishing this article.

\section{Funding Information}

Article publication was funded by Universiti Utara Malaysia.

\section{Author's Contributions}

Zurni Omar: Worked on the drafting, reading and approval of final manuscript.

Oluwaseun Adeyeye: Proposed, derived and developed a code for implementing the method.

\section{Ethics}

The authors declare that there is no conflict of interests regarding the publication of the paper.

\section{References}

Adesanya, A.O., B. Abdulqadri and Y.S. Ibrahim, 2014. Hybrid one step block method for the solution of third order initial value problems of ordinary differential equations. Int. J. Applied Math. Comput., 6: 10-16. DOI: 10.12732/ijpam.v97i1.1

Adesanya, A.O., T.A. Anake and M.O. Udoh, 2008. Improved continuous method for direct solution of general second order ordinary differential equation. J. Nigerian Assoc. Math. Phys., 13: 59-62.

Areo, E.A. and R.B. Adeniyi, 2013. A self starting linear multistep method for direct solution of initial value problems of second order ordinary differential equations. Int. J. Pure Applied Math., 82: 345-364.

Awoyemi, D.O. and O.M. Idowu, 2005. A class of hybrid collocation methods for thirdorder ordinary differential equations. Int. J. Comput. Math., 82: 1287-1293. DOI: 10.1080/00207160500112902

Badmus, A.M., Y.A. Yahaya and Y.C. Pam, 2015. Adams type hybrid block methods associated with chebyshev polynomial for the solution of ordinary differential equations. British J. Math. Comput. Sci., 6: 464-474. DOI: 10.9734/BJMCS/2015/14945

Butcher, J.C., 2008. Numerical Methods for Ordinary Differential Equations. 2nd Edn., John Wiley and Sons, Chichester, ISBN-10: 0470753757, pp: 482.

Fatunla, S.O., 1988. Numerical Methods for Initial Value Problems in Ordinary Differential Equations. 1st Edn., Academic Press, Boston, pp: 295.

Hasni, M.M., Z.A. Majid and N. Senu, 2013. Numerical solution of linear dirichlet two-point boundary value problems using block method. Int. J. Pure Applied Math., 85: 495-506. DOI: 10.12732/ijpam.v85i3.6

James, A.A., O.A. Adesanya and K.M. Fasasi, 2013. Starting order seven method accurately for the solution of first initial value problems of first order ordinary differential equations. Progress Applied Math., 6: 30-39. DOI: 10.3968/j.pam.1925252820130601.5231

Jator, S.N. and J. Li, 2012. An algorithm for second order initial and boundary value problems with an automatic error estimate based on a third derivative method. Numerical Algorithms, 59: 333-346.

DOI: $10.1007 / \mathrm{s} 11075-011-9492-3$ 
Kayode, S.J. and O. Adeyeye, 2011. Two-step twopoint hybrid methods for general second order differential equations. Afr. J. Math. Comput. Sci. Res., 6: 191-196.

Lambert, J.D., 1973. Computational Methods in Ordinary Differential Equations. 1st Edn., Wiley, Chichester, ISBN-10: 0471511943, pp: 278.

Omar, Z., 2004. Developing parallel 3-point implicit block method for solving second order ordinary differential equations directly. Int. J. Manage. Stud., 11: 91-103.

Omar, Z. and J.O. Kuboye, 2015. Computation of an accurate implicit block method for solving third order ordinary differential equations directly. Global J. Pure Applied Math., 11: 177-186.
Shokri, A. and A.A. Shokri, 2013. The new class of implicit L-stable hybrid Obrechkoff method for the numerical solution of first order initial value problems. Comput. Phys. Commun., 184: 529-531.

Sunday, J., M.R. Odekunle and A.O. Adesanya, 2013. Order six block integrator for the solution of firstorder ordinary differential equations. Int. J. Math. Soft Comput., 3: 87-96. 